\title{
Three Paradoxes with The Cobb-Douglas Production Function
}

\author{
Ahmet Özçam ${ }^{1}$ Dilek Sağlık Özçam²* \\ 1. Department of Economics, Yeditepe University, 26 Ağustos Yerleşkesi, Kayışdağı cad.,İnönü Mah. \\ Membağ sok. 34755, Kadikoy, Istanbul, Turkey \\ 2. Department of Human Resources, Yeditepe University, 26 Ağustos Yerleşkesi, Kayışdağı cad.,İnönü \\ Mah. Membağ sok. 34755, Kadikoy, Istanbul, Turkey
}

\begin{abstract}
The output elasticities of inputs seem all about what an applied researcher is concerned with. The Cobb-Douglas production functions formulae possess the convenient property that the exponents of inputs readily represent the output elasticities of inputs such that the sum of these exponents reveal whether there are increasing, constant or decreasing returns to scale. However, there are also some inconveniencies with this type of production functions. In this paper we will investigate three of them. First of all, the short run marginal cost functions obtained from the Cobb-Douglas type of production functions can be both convex and concave depending on the magnitude of the technical coefficient of labor input. Unfortunately, this awkward behavior cannot be explained with the economic theory. Secondly, when the variable input labor with a given level of Technical productivity is complemented with a once-and-for-all increase in the amount of physical capital input, the labor becomes more and more productive as the usage of labor increases. This clearly stands in contrast with the Law of Diminishing Marginal Returns. Finally, we find ever-increasing returns to 'Technical productivity of labor', keeping the amounts of labor and physical capital constant, which is again surprising.
\end{abstract}

Key words: paradox; convex and concave marginal costs; Cobb-Douglas production function; increasing rate of return to Technical productivity of labor.

JEL classification: D2, D3, D4.

DOI: $10.7176 / \mathrm{EJBM} / 11-1-12$

\section{INTRODUCTION}

In this paper, we will investigate the Cobb-Douglas production function in the short run when the physical capital input is fixed. It seems that an applied researcher typically considers only the output elasticities of inputs. This piece of information is sufficient to conclude whether there are increasing, decreasing or constant returns to scale in the long run. Unfortunately some characteristics of the Cobb-Douglas function seem to be problematic. They seem to stand in contrast with the basic economic knowledge. As far as the Cobb-Douglas types of production function are predominantly used in applied econometrics, we must be able to make economic sense with respect to all of their aspects, not only with respect to the output elasticities of inputs.

In section 2 below, we will present 3 propositions discussing some anomalies regarding the behavior of the Cobb-Douglas production functions. These will be with respect to the marginal cost, once-and-for-all increase in the amount of physical capital input coupled with increasing amount of labor and ever-increasing returns to 'Technical productivity of labor'. Section 3 concludes the paper.

\section{THE COBB-DOUGLAS PRODUCTION FUNCTION, MARGINAL COST AND THE PRODUCTIVITY OF LABOR: SOME PARADOXES}

In the short run, the Cobb-Douglas Production function is,

$$
y=\operatorname{labor}^{a} * \overline{\text { capital }}^{b}
$$

where labor and $\overline{c a p t t a l}$ are the amounts of labor and physical capital inputs, and $a$ and $b$ are some technical coefficients of the production function. We assume that the amount of physical capital, $\overline{\text { capttal }}$, is fixed in the short run. 
The coefficient, $a$, is known as the elasticity of labor with respect to output which means that if labor is increased by some percentage, say $x$, the output increases by $a^{*} x$ percent. $^{2}$ For example, for $x$ is equal to $10 \%$ and $a=0.8$ we have

$$
\begin{aligned}
y(x=1.1, a & =0.8)=(1.1 * \text { labor })^{0.8} *{\overline{\text { capital }^{b}}}^{b}=1.1^{0.8} * \text { labor }^{0.8} *{\overline{\text { capital }^{b}}} \\
& \approx 1.08 * \text { labor }^{0.8} * \overline{\text { capltal }}^{b}
\end{aligned}
$$

since $1.1^{0.8} \approx 1.08$. So, the elasticity of labor with respect to output is constant no matter what the initial amounts of labor or capital are. In the economics literature, the logarithms of both sides of Eq.1 above are taken to linearize the production function to facilitate the estimation and to show that the constant slope coefficient, $a$, is the elasticity term. However, given the estimation capability of today's computer packages, a direct (without using the logarithms) non-linear estimation is also possible. This property of the coefficient $a$, seems all about what an applied researcher is concerned with. In the case where this production function refers to the long run then in addition to labor the physical capital is also variable. The applied researcher conclude that there is increasing returns to scale if $a+b>1$ and that decreasing returns to scale if $a+b<1$ and constant returns to scale if $a+b=1$.

In this paper, we will consider two types of productivity efficiency with respect to labor input:

i) Technical productivity of labor: the a coefficient in Eq.1 above representing education, skills, training...of the labor. This is also the elasticity of labor with respect to output as explained above.

ii) Return to increased amount of labor: that is when the amount of labor (labor personnel) is increased. Here, the most important assumption in the short run is the Law of Diminishing Marginal Returns (LDMR) which states that as the amount of labor is increased while the amount of physical capital is held constant, there must be diminishing returns to the extra amounts of labor. Therefore, the technical productivity coefficient , $a$ in (i) above is restricted to be between zero and one, i.e. $0<a<1$.

In Sections 2.1, 2.2 and 2.3 below we will discuss three anomalies related to the familiar Cobb-Douglas type of production functions.

\subsection{THE ABNORMAL DUAL CONVEX AND CONCAVE BAHAVIOR OF THE MARGINAL COST FUNCTION OF A COBB-DOUGLAS TYPE PRODUCTION FUNCTION}

Assume that a perfectly competitive firm maximizes its profits in the short run.

$$
\begin{gathered}
\text { Maximize } \pi=p * y-w * L-r * \bar{K} \\
\text { subject to } y=L^{a} * \bar{K}^{b} \text { (production function) }
\end{gathered}
$$

where $\pi, p, y, w, r, L, \bar{K}$ are the profits, the price of the product, the output, the wage rate, the rent price of capital, the labor input and the fixed amount of physical capital of the firm respectively. $a$ and $b$ are the technical coefficients of the Cobb-Douglas production function. In the short run, when we solve the production function constraint in terms of labor, $L_{c}(y, a, b, \bar{K})=y^{\frac{1}{a}} * \bar{K}^{\frac{-b}{a}}$, we obtain the short run conditional demand for labor for a given level of output, $y$. Then, the short run total costs of the firm, $T C(\ldots)$ is:

$$
T C(y, a, b, \bar{K}, w, r)=L_{c}(y, a, b, \bar{K}) * w+\bar{K} * r=y^{\frac{1}{a}} * \bar{K}^{\frac{-b}{a}} * w+\bar{K} * r
$$

and its marginal cost is: 2 or $a$ is the partial elasticity of labor if the capital input is variable in the long run where the amount of physical capital is
variable. 


$$
M C(y, a, b, \bar{K}, w)=\left(\frac{1}{a}\right) * y^{\frac{1-a}{a}} * \bar{K}^{\frac{-b}{a}} * w
$$

PROPOSITION-1: With the Cobb-Douglas types of production functions, the marginal cost is convex if the productivity coefficient of labor is $0<a<0.5$ and is concave if $1>a>0.5$. The marginal cost is linear if $a=0.5$ and a constant function if $a=1$.

Proof: If $a=0.5$, the marginal cost is $\left(2 * y * \bar{K} \frac{-b}{0.5} * w\right)$ and therefore linear and upward sloping and if $a=1$, it is a constant function equal to $\left(\bar{K}^{-b} * w\right)$.

The first derivative of the marginal cost $M C(\ldots)$ is:

$$
\frac{d M C(y, a, b, \bar{K}, w)}{d y}=\left(\frac{1}{a}\right) *\left(\frac{1-a}{a}\right) * y^{\frac{1-2 a}{a}} * \bar{K}^{\frac{-b}{a}} * w>0
$$

and therefore the marginal cost is strictly increasing in $y$. The second derivative of the marginal cost $M C(\ldots)$ is:

$$
\frac{d^{2} M C(y, a, b, \bar{K}, w)}{d y^{2}}=\left(\frac{1}{a}\right) *\left(\frac{1-a}{a}\right) *\left(\frac{1-2 a}{a}\right) y^{\frac{1-3 a}{a}} * \bar{K}^{\frac{-b}{a}} * w
$$

the term $\left(\frac{1-2 a}{a}\right)$ is positive if $0<\mathrm{a}<0.5$, and it is negative if this term is $0.5<\mathrm{a}<1 .{ }^{3}$ Since a positive second derivative implies that the marginal cost is convex with respect to output (or that the first derivative of the marginal cost is increasing) and a negative second derivative implies that the marginal cost is concave with respect to output (or that the first derivative of the marginal cost is decreasing), this completes the proof.

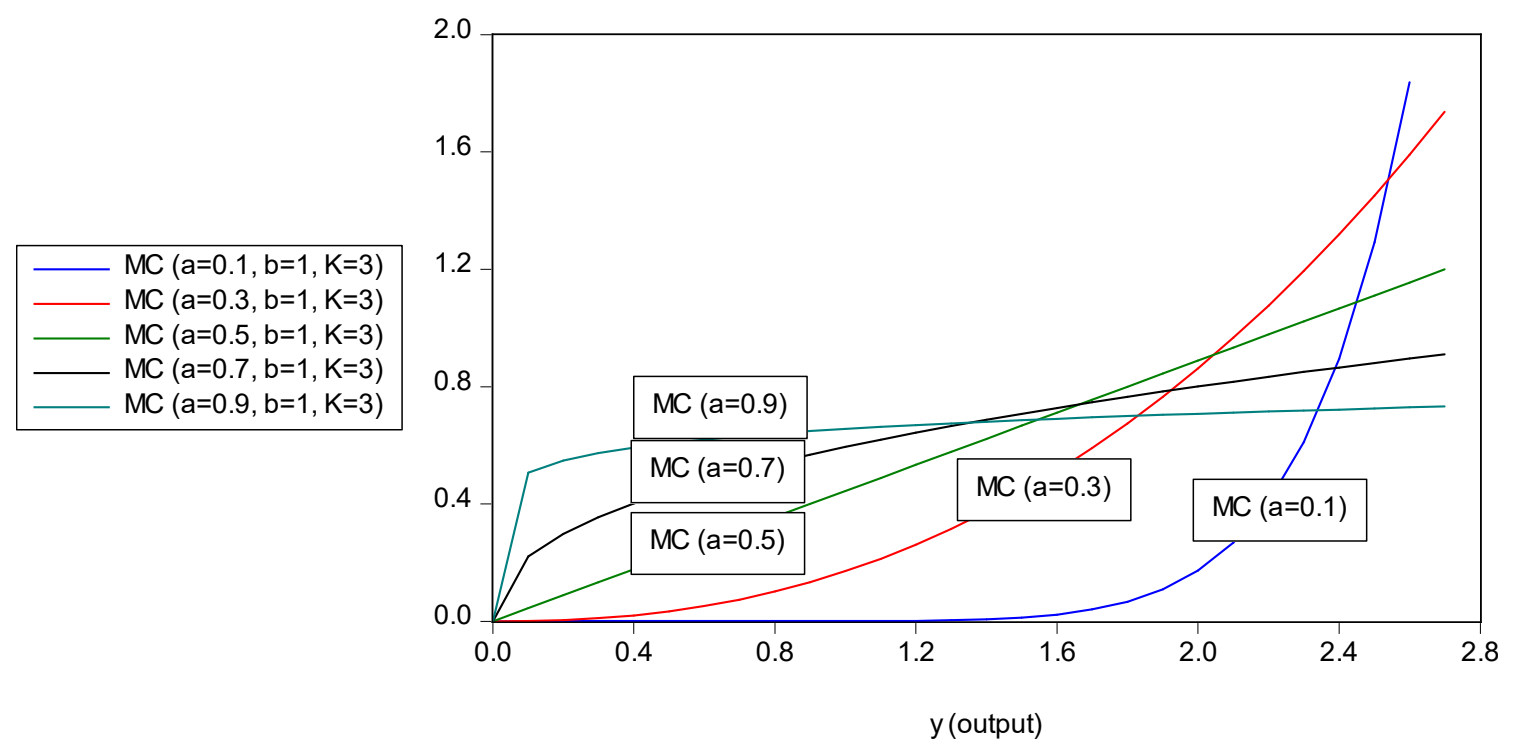

FIGURE-1 THE MARGINAL COST FUNCTIONS OF THE COBB-DOUGLAS PRODUCTION FUNCTIONS

$(a=0.1,0.3,0.5,0.7,0.9 . b=1, w=2$, and $\overline{\text { capital }}=3)$

\footnotetext{
3 The second derivative of the marginal cost is zero when $a=0.5$ or 1 , which corresponds to linear and upward sloping and constant marginal costs respectively.
} 
In Figure-1 above, we show five marginal cost (MC) functions obtained from Cobb-Douglas type production functions with the technical coefficients $a=0.1,0.3,0.5,0.7,0.9$ and $b=1$ and the amount of physical capital $K=3$ in each case as an illustration. As claimed and proved in Proposition- 1 above, the MC's with $a=0.1,0.3$ are convex in output and the MC's with $a=0.7,0.9$ are concave in output. Hence, we argue that this is the first anomaly that we find with the Cobb-Douglas type of production functions used in economics. The MC switches from convexity to concavity depending whether the technical coefficient $a$ is less than 0.5 or greater than 0.5 . This is a mathematical property of Cobb-Douglas production functions which gives rise to such suddenly changing shapes of marginal cost functions and unfortunately, it seem very likely that we cannot explain this abnormal behavior using neither economic theory nor real-world data justifying it.

\subsection{THE IMPACT OF A ONCE-AND-FOR-ALL INCREASE IN PHYSICAL CAPITAL}

The vertical distance between 2 Cobb-Douglas types of functions with the same Technical productivity of labor, or coefficient $a$, but with different levels of fixed capital opens up as more labor is used. For example in Figure-2 below, the vertical difference between the production functions, y_a04_K5 and y_a04_K3 is higher when the amount of labor increases on the horizontal axis.

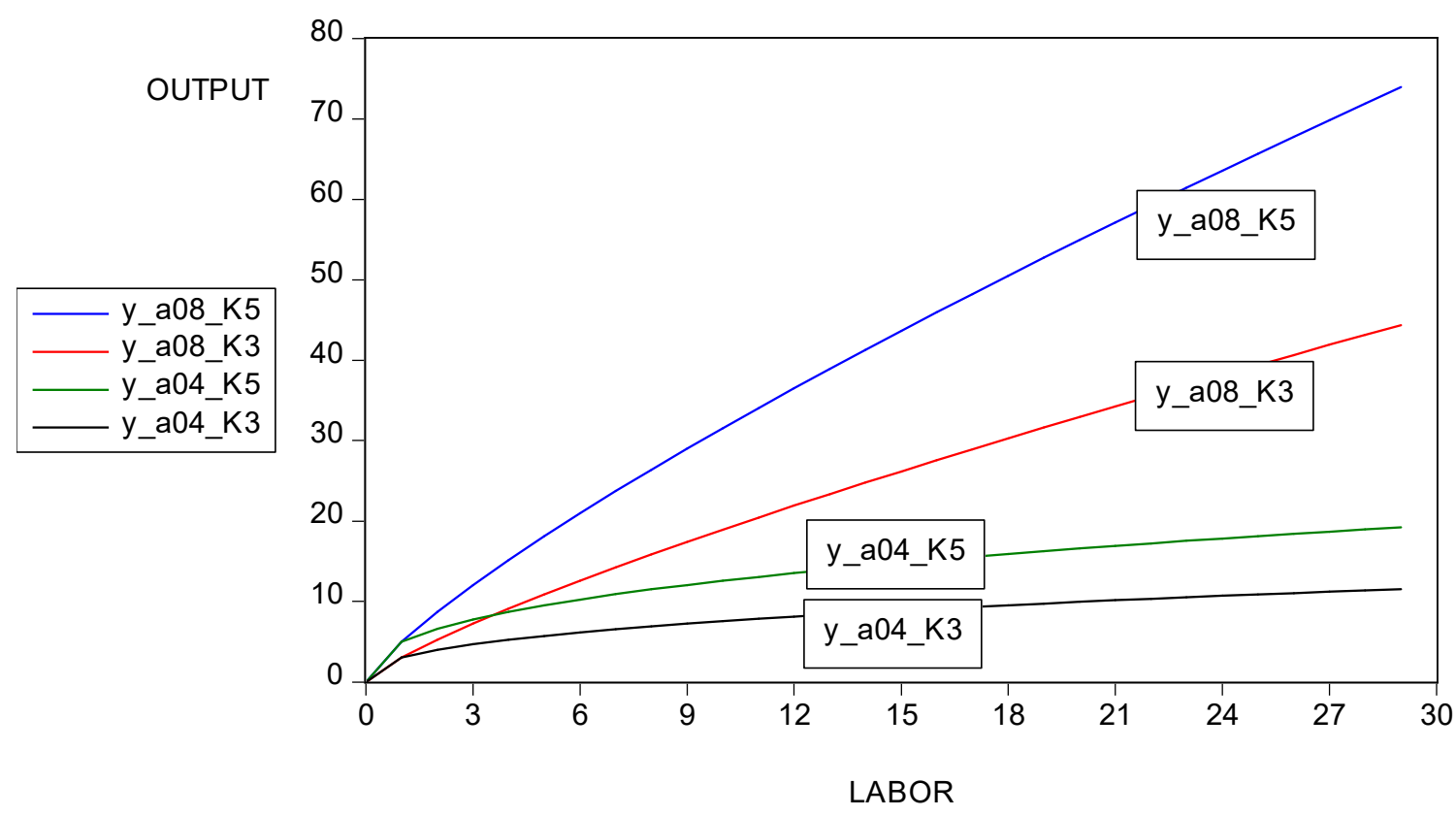

FIGURE-2 THE COBB-DOUGLAS PRODUCTION FUNCTIONS IMPACT OF A ONCE-AND-FOR-ALL INCREASE IN PHYSICAL CAPITAL

$$
(a=0.4,0.8, b=1,(\overline{\text { capital }}=3 \text { and } 5 \text { units })
$$

We have this widening gap result, since the difference in two Cobb-Douglas types of production functions with the same Technical productivity of labor, or coefficient $a$, but different amounts of physical capital, is:

$$
\begin{gathered}
y\left(a, \overline{\text { capital_hıgh }}^{b}\right)-y\left(a, \overline{\text { capital_low }}^{b}\right)=\text { labor }^{a} * \overline{\text { capital_high }}^{b}-\text { labor }^{a} * \overline{\text { capital_low }}^{b} \\
=\text { labor }^{a} *\left(\overline{\text { capital_high }^{b}}-\overline{\text { capıtal_low }}^{b}\right)
\end{gathered}
$$


and this difference increases indefinitely when labor increases for $0<a<1$. This is true since the derivative of the difference in the production functions in Eq. 8 above is positive, i.e. $a *$ labor $^{a-1} *\left(\overline{\text { capltal_hlgh }}^{b}-\right.$ $\left.\overline{\text { capltal_low }}^{b}\right)>0$, indicating that the difference is getting larger and larger as the amount of labor increases. In economic terms, this means that with the same extra amount of physical capital, labor contributes increasingly more to production, as more labor is used. This seems again to be another paradox in view of the Law of Diminishing Marginal Returns (LDMR)! We summarize this contradiction in the following proposition:

PROPOSITION-2: When the variable input labor with a given level of Technical productivity is complemented with a once-and-for-all increase in the amount of physical capital input, the labor becomes more and more productive as the usage of labor increases.

Proof: It is proved in Eq.8 above, and the following discussion.

\subsection{EVER-INCREASING RETURNS TO TECHNICAL PRODUCTIVITY OF LABOR}

Finally, the higher the Technical productivity of labor, or coefficient $a$, the higher is the difference in production levels, for a given level of labor. For example in Figure-3 below, the vertical difference between

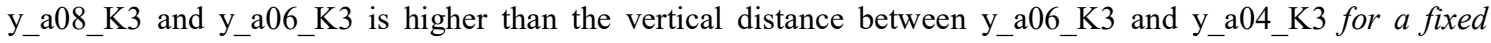
amount of labor, and in turn this last difference is larger than the difference between $\mathrm{y}_{-} \mathrm{a} 04 \_\mathrm{K} 3$ and $\mathrm{y}_{-} \mathrm{a} 02 \_\mathrm{K} 3$.

We have this result since there always exists a real number $r$ such that $\exp (r)=$ labor $^{a}$ (for labor $>$ 1). Then $r=\ln (\exp (r))=\ln \left(\right.$ labor $\left.^{a}\right)=a * \ln ($ labor $)$.

$$
\frac{d\left(\text { labor }{ }^{a} \bar{K}^{b}\right)}{d a}=\exp (a * \ln (\text { labor })) * \ln (\text { labor }) * \bar{K}^{b}>0
$$

as long as labor $>1$ and

$$
\begin{aligned}
& \frac{d^{2}\left(\text { labor }{ }^{a} \bar{K}^{b}\right)}{d a^{2}}=\exp (a * \ln (\text { labor })) *(\ln (\text { labor }))^{2} * \bar{K}^{b}>0 \\
& =\operatorname{labor}^{a} *(\ln (\text { labor }))^{2} * \bar{K}^{b}>0
\end{aligned}
$$

In other words, the Cobb-Douglas function, labor ${ }^{a} \bar{K}^{b}$, is convex in the variable, $a$. This implies that the increase in the function gets higher as the Technical productivity of labor, or coefficient $a$, increases, keeping the levels of labor and physical capital constant. This again seems to be a paradox since it indicates an everincreasing returns to technical productivity of labor! We summarize this third contradiction in the following proposition: 


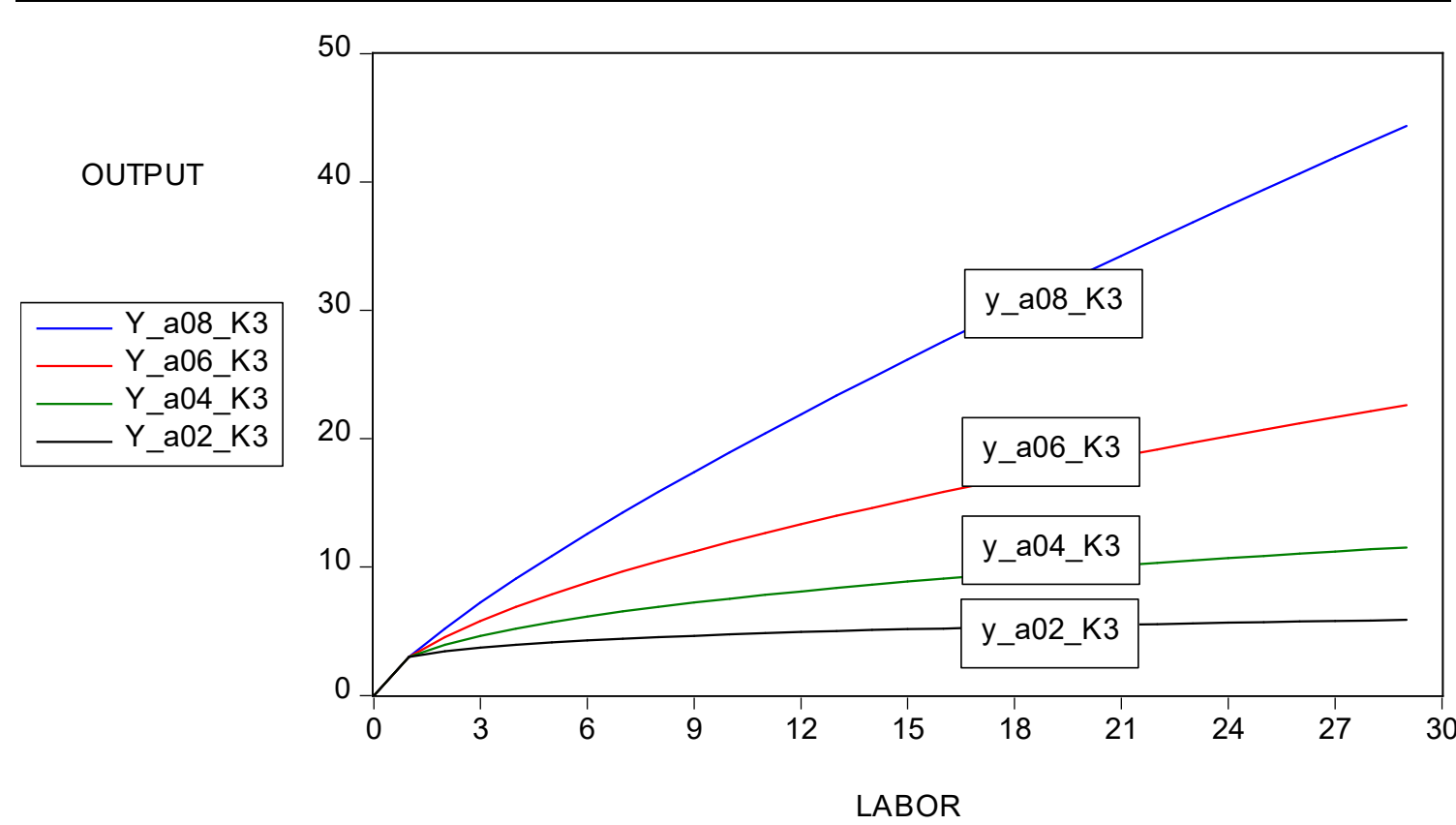

FIGURE-3 THE COBB-DOUGLAS PRODUCTION FUNCTIONS

EVER-INCREASING RETURNS TO TECHNICAL PRODUCTIVITY

OF LABOR

$(a=0.2,0.4,0.6,0.8, b=1,(\overline{\text { capltal }}=3$ units $)$

PROPOSITION-3: There seems to be ever-increasing returns to 'Technical productivity of labor', keeping the amounts of labor and physical capital constant.

Proof: It is shown in Eq.9 above.

\section{CONCLUSION}

In this paper, we investigated the Cobb-Douglas production functions with regard to the short run paying a particular attention especially to the technical production coefficient of the labor input. Inasmuch as the CobbDouglas types of production function are predominantly used in applied econometrics, they must make economic sense in all aspects, not only with respect to the output elasticities of inputs.

We made the following 3 propositions:

PROPOSITION-1: With the Cobb-Douglas types of production functions, the marginal cost is concave or convex depending on the Technical productivity coefficient of labor: whether this coefficient is greater or less than 0.5 .

Unfortunately, it is almost impossible to attach any economic intuition to such abrupt shape-changing marginal cost function obtained from the Cobb-Douglas type of production function. 
PROPOSITION-2: When the variable input labor with a given level of Technical productivity is complemented with a once-and-for-all increase in the amount of physical capital input, the labor becomes more and more productive as the usage of labor increases.

With regard to Proposition-2 above, it means that the shift in the production function is greater at higher levels of employment than at lower levels, when the same extra amount of physical capital (once-and-for all) is added to the production process. Alternatively, we can say that a higher amount of capital contributes more and more to the production process if coupled with more labor. However, this again seems to be a contradiction! How can the same extra amount of capital produce more and more output coupled with increasing amounts of labor which must obey the law of diminishing marginal returns?

PROPOSITION-3: There seems to be ever-increasing returns to 'Technical productivity of labor', keeping the amounts of labor and physical capital constant.

Finally, with respect to the third one, we must accept that whereas there are diminishing returns to labor as dictated by the Law of Diminishing Marginal Returns (LDMR), there are increasing returns to the Technical productivity of labor, which is again surprising.

These results seem to be a characteristic of the Cobb-Douglas production function where the two inputs are combined in a multiplicative way in the functional form. Whether such phenomena occur in real world is an issue that should be checked in applied work. If they are true, we believe that they also deserve being Laws of economics. 